\title{
Copper-Catalyzed Direct Sulfoximination
}<smiles>COc1ccc(-c2nnco2)cc1</smiles><smiles>CS(=N)(=O)c1ccccc1</smiles>

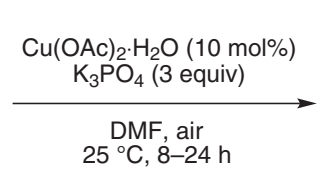<smiles>COc1ccc(-c2nnc(N=S(C)(=O)c3ccccc3)o2)cc1</smiles>

copper<smiles>CS(=O)(=Nc1nnc(-c2ccc(C(F)(F)F)cc2)o1)c1ccccc1</smiles><smiles>CS(=O)(=O)Nc1nnc(-c2ccc(Cl)cc2)o1</smiles>

$90 \%$ yield<smiles>NS(=O)(=O)c1nnc(-c2ccccc2)o1</smiles>

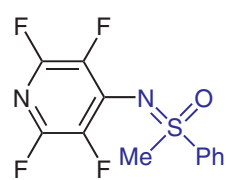

$92 \%$ yield<smiles>C[SH](=O)(P)Nc1nc2ccccc2s1</smiles>

$73 \%$ yield<smiles>CS(=O)(=Nc1nc2ccccc2o1)c1ccccc1</smiles>

$91 \%$ yield, >99\% ee
Significance: Herein, the direct dehydrogenative sulfoximination of azoles and polyfluoroarenes is reported. This copper acetate catalyzed $\mathrm{C}-\mathrm{N}$ coupling proceeds effectively at room temperature in air and affords a wide range of $\mathrm{N}$-arylsulfoximines in excellent yield. With this protocol, a preactivation step, such as halogenation or the formation of a metalated species, is not necessary.
Comment: The use of other copper salts gave similar or slightly inferior results. The addition of different ligands leads to decreasing yields. For a full conversion the combination of the phosphate base and DMF was necessary. Using an enantiopure sulfoximine gave the desired product maintaining the enantiomeric excess. 